\title{
Protective effects of selenium on Bisphenol A-induced oxidative stress in mouse testicular mitochondria and sperm motility
}

\author{
Zeinab Rafiee ${ }^{1}$, Fatemeh Rezaee-Tazangi², Leila Zeidooni ${ }^{3}$, Hadis Alidadi ${ }^{3}$, Layasadat Khorsandi ${ }^{2,4}$ \\ ${ }^{1}$ Student Research committee, Ahvaz Jundishapur University of Medical Sciences, Ahvaz, Iran \\ 2Department of Anatomical Sciences, Ahvaz Jundishapur University of Medical Sciences, Ahvaz, Iran \\ ${ }^{3}$ Toxicology Research Center, Medical Basic Sciences Research Institute, Ahvaz Jundishapur University of Medical \\ Sciences, Ahvaz, Iran \\ ${ }^{4}$ Cellular and Molecular Research Center, Medical Basic Sciences Research Institute, Ahvaz Jundishapur \\ University of Medical Sciences, Ahvaz, Iran
}

\begin{abstract}
Objective: This study aimed to explore the impact of selenium (SE) on Bisphenol-A (BPA)-exposed sperm and isolated testicular mitochondria of mice.

Methods: Mouse sperm and isolated mitochondria were exposed to BPA $(0.8 \mathrm{mM})$ and different concentrations of SE $(50,100$, and $200 \mu \mathrm{M})$ for four hours. The viability of sperm and isolated mitochondria as well as the mitochondrial membrane potential (MMP) were evaluated. SOD (superoxide dismutase), GSH (glutathione), MDA (malondialdehyde), and ROS (reactive oxygen species) levels in testicular mitochondria were also examined.

Results: BPA concentration-dependently enhanced ROS and MDA levels in isolated mitochondria, while MMP and acclivity of GSH and SOD significantly reduced. BPA also considerably impaired spermatozoa survival and motility. SE concentration-dependently reduced mitochondrial oxidative stress, MMP, sperm survival, and total sperm motility.

Conclusions: Our findings collectively suggested that SE concentration-dependently reversed BPA-caused mitochondrial toxicity and reduced sperm motility by suppressing oxidative stress.
\end{abstract}

Keywords: selenium, sperm motility, oxidative stress, Bisphenol A

\section{INTRODUCTION}

Bisphenol A (BPA), an industrial chemical, is used to produce polycarbonate (a clear and hard, plastic) and epoxy resins (lining on the inside of beverage cans and metal-based foods (Mikołajewska et al., 2015). BPA is also used in the manufacturing of toys, eyeglasses, lenses, compact discs, thermal paper, and dental sealants (Löfroth et al., 2019). BPA penetrates the body through ingestion, dermal contact or inhalation (Konieczna et al., 2015). The exposure of humans to BPA has been related to biological systems, environmental BPA, and food intake (Engel et al., 2014). BPA has been found in amniotic fluid, semen, plasma, urine, and breast milk (Ikezuki et al., 2002).

Evidence indicates that BPA has deleterious effects on the reproductive system (Anjum et al., 2011; Ullah et al., 2018). BPA diminishes the weight of the epididymis and testicles and impairs sperm quality of rodents (Chitra et al., 2003; Tyl et al., 2008; Knez et al., 2014). Moreover, BPA impairs mitochondrial function by diminishing ATP, reducing mitochondria mass, and disrupting the mitochondrial membrane potential (MMP) (Kaur et al., 2018). Mitochondrial dysfunction affects sperm production and spermatozoa motility (Kamali Sangani et al., 2017). Besides, BPA diminishes antioxidant levels and stimulates ROS generation in testicular tissue (Chitra et al., 2003).
Selenium (2-aminoethanesulfonic acid, SE), an essential trace element with antioxidant properties, is involved in successful male reproduction due to its role in testosterone synthesis and development of spermatozoa (Khurana et al., 2019). SE plays a key role in spermatogenesis and sperm motility (Das \& Ghosh, 2010). Sperm SE content has been positively correlated with the volume of mitochondria in humans and several animal species, such as boars, horses, bulls, and rams (Saaranen et al., 1989). SE exists in the outer membrane of the sperm mitochondria as selenoproteins (Calvin et al., 1981). Thus, SE deficiency impairs sperm motility and morphology and leads to infertility (Ursini et al., 1985). SE improves sperm numbers and motility by selenoproteins (Kaur \& Bansal, 2015).

This study looked into the effects of SE on BPA-induced mitochondrial toxicity and impaired mouse sperm motility.

\section{MATERIALS AND METHODS}

\section{Experimental design (Figure 1)}

Samples of sperm and isolated testicular mitochondria were collected from 48 NMRI mice aged 8-10 weeks. The Ethics Committee on Animal Research approved this study (certificate: ABHC.REC.1397-079).

Spermatozoa were isolated from the epididymis of the mice and divided into six groups, as follows $\left(5 \times 10^{6} \mathrm{sperm} /\right.$ $\mathrm{ml}$ were used in each group):

Group I. (Control): treated with medium only

Group II. (BPA): treated with $0.8 \mathrm{mM}$ BPA for two hours

Groups III-V: exposed to 50, 100, and $200 \mu \mathrm{M}$ SE, respectively, for two hours before exposure to BPA.

Group VI (SE): exposed to $200 \mu \mathrm{M}$ SE for four hours

The untreated spermatozoa died after four hours. Thus, a total incubation time of four hours was set for exposure of sperms to SE or BPA. BPA (Sigma) or SE (Sigma) was dissolved in dimethyl sulfoxide (DMSO, $0.1 \%$ ) and diluted in Ham's F-10 media (Invitrogen). BPA concentrations were based on the results of the MTT test (Table 1). Isolated mitochondria and sperm were exposed to DMSO (1\%) for four hours to assess the safety of DMSO by MTT test. DMSO had no toxic effect on isolated mitochondria or mouse sperm (Table 2).

\section{Mitochondria isolation}

The testicular tissue of euthanatized mice was dissected and minced in medium containing fat free bovine serum albumin $(0.1 \%)$, sucrose $(250 \mathrm{mM})$, EGTA $(0.2 \mathrm{mM})$, EDTA $(0.1 \mathrm{mM})$, and HEPES-KOH $(5 \mathrm{mM})$. The minced testicles were homogenized and centrifuged at $3,000 \cdot \mathrm{g}$ (10 minutes at $4^{\circ} \mathrm{C}$ ). The supernatant was centrifuged for 7 minutes at $10,000 \cdot \mathrm{g}$. The prepared mitochondrial fractions were centrifuged for 6 minutes at $10,000 \cdot \mathrm{g}$ (twice). The amount of protein was determined using Bradford reagent (Invitrogen). Isolated mitochondria ( $0.5 \mathrm{mg}$ protein/ $\mathrm{mL}$ ) was treated with BPA or SE. 

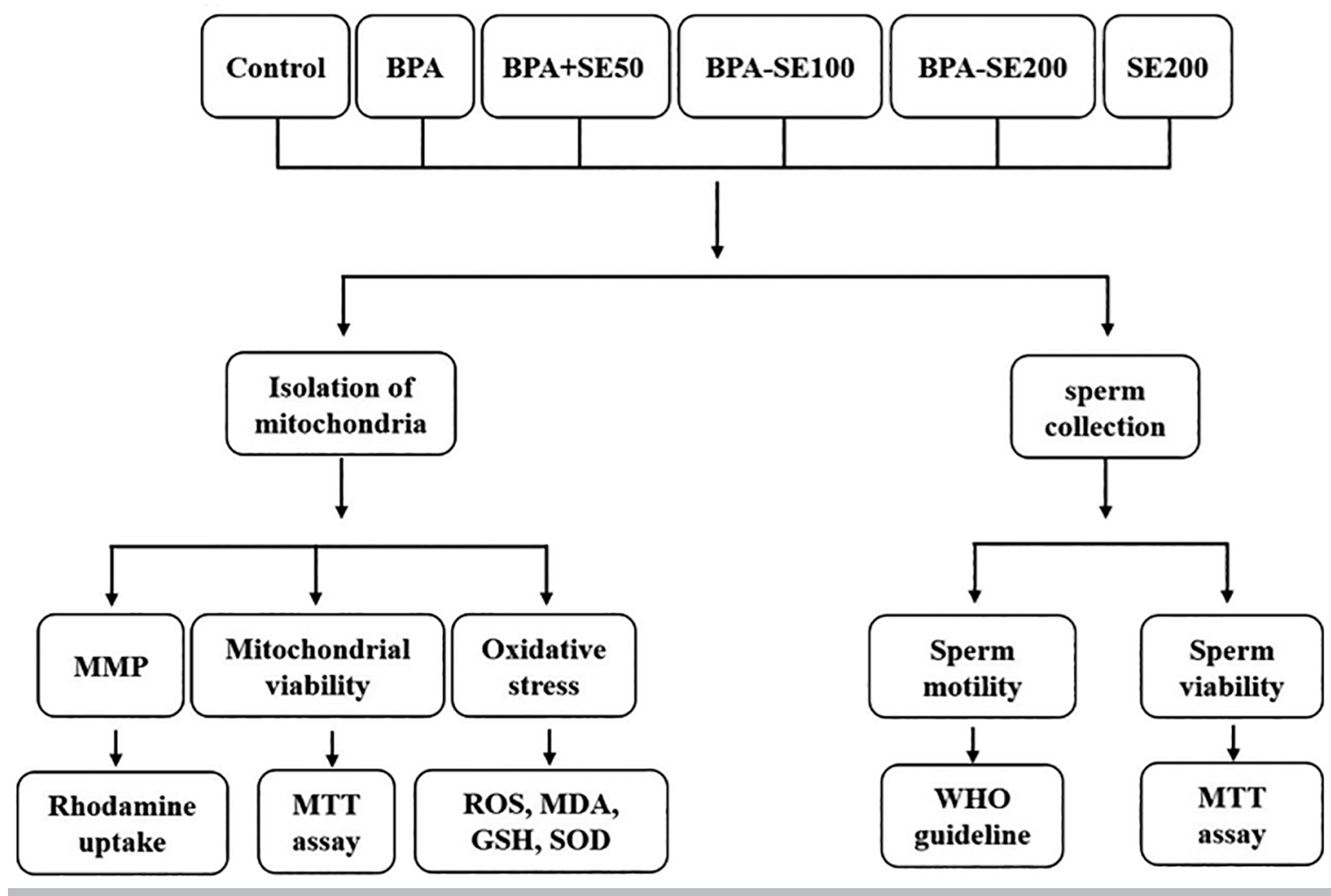

Figure 1. Schematic illustration detailing the experimental design of the study.

Table 1. The effect of different concentrations of BPA on spermatozoa viability

\begin{tabular}{|l|c|c|}
\hline Concentrations & 1 hour & 2 hours \\
\hline 0 (control) & $100.00 \pm 0.00$ & $100.00 \pm 0.00$ \\
\hline $0.1 \mu \mathrm{M}$ & $98.4 \pm 2.15$ & $95.7 \pm 3.23$ \\
\hline $0.2 \mu \mathrm{M}$ & $92.1 \pm 5.41$ & $86.3 \pm 4.45$ \\
\hline $0.4 \mu \mathrm{M}$ & $76.5 \pm 5.36$ & $65.9 \pm 4.58$ \\
\hline $0.8 \mu \mathrm{M}$ & $63.9 \pm 4.12^{*}$ & $49.8 \pm 3.81 * *$ \\
\hline $1 \mu \mathrm{M}$ & $56.7 \pm 3.72^{*}$ & $35.1 \pm 3.09 * *$ \\
\hline
\end{tabular}

Values are expressed as mean \pm SD $(n=6) .{ }^{*} p<0.05$, $* * p<0.01 ; *$ comparison against controls.

\section{MTT assay}

Spermatozoa or mitochondrial fractions were placed in 96-well plates and exposed to SE or BPA. After treatment, $5 \mathrm{mg} / \mathrm{mL}$ MTT (Sigma, USA) was added to the wells and kept for one hour at $37^{\circ} \mathrm{C}$. Then the medium was removed, and DMSO $(100 \mu \mathrm{L})$ added to each well. A micro-plate reader was used to read absorbance at $570 \mathrm{~nm}$.

Determining MDA content, ROS formation, and antioxidant levels

The treated mitochondria was poured into the micro-tubes and $10 \mu \mathrm{M}$ DCFH-DA (Sigma) plus Hank's buffered salt solution $(100 \mu \mathrm{L})$ was added and kept at $37^{\circ} \mathrm{C}$ for 40 minutes. A spectrofluorometer (LS50B, USA, Em: $570 \mathrm{~nm}$; Ex: $490 \mathrm{~nm}$ ) was used to examine ROS levels. Protein content of the treated mitochondrial fraction was measured using Bradford reagent (Invitrogen). Malondialdehyde (MDA), superoxide dismutase (SOD), and GSH (glutathione) activities were evaluated based on the kit's guidelines (ZellBio Company).

\section{ation \\ Mitochondrial membrane potential (MMP) evalu-}

The treated mitochondria ( $0.4 \mathrm{mg}$ protein $/ \mathrm{mL}$ ) was incubated in $10 \mu \mathrm{M}$ Rhodamine 123 for 15 minutes. A spectrophotometer (LS50B, USA; emission: $535 \mathrm{~nm}$; excitation: $490 \mathrm{~nm}$ ) was used to measure fluorescence.

\section{Sperm motility}

Sperm motility was evaluated according to WHO guidelines. Sperm suspensions $(10 \mu \mathrm{L})$ were poured in the semen analysis chamber. Six fields were examined to rate the motility of at least 200 spermatozoa for each specimen. Percent sperm movement was evaluated to estimate the proportions of fast progressive $(A)$, slow progressive $(B)$, no progressive (C), and immotile sperm (D).

\section{Statistical Analysis}

One-way analysis of variance was performed in SPSS (version 22.0) followed by post-hoc pairwise comparison; $p$-values $<0.05$ were deemed significant.

\section{RESULTS}

\section{MTT assay}

Following exposure to BPA, percent viability decreased considerably in spermatozoa and testicular mitochondria fractions $(p<0.01)$. Survival rates grew considerably in the SE-treated mitochondria and spermatozoa $(p<0.05)$. SE concentration-dependently elevated survival of the BPA-treated spermatozoa and mitochondrial fractions (Figure 2).

\section{levels}

MDA content, ROS formation, and antioxidant

Following exposure to BPA, ROS production and MDA levels increased considerably in mitochondrial fractions $(p<0.01)$. MDA level and ROS production of the 


\begin{tabular}{|l|c|c|}
\hline Table 2. Effects of DMSO on testicular mitochondria and spermatozoa & Control \\
\hline Parameters & $100 \pm 0.00$ & $100.01 \pm 1.4$ \\
\hline Viability of sperms (\%) & $100 \pm 0.00$ & $99.5 \pm 1.2$ \\
\hline Viability of mitochondria (\%) & $100 \pm 0.00$ & $100.03 \pm 1.1$ \\
\hline MMP (\% of control) & $100 \pm 0.00$ & $98.9 \pm 2.3$ \\
\hline ROS formation (\% of control) & $17.6 \pm 5.6$ & $17.4 \pm 3.6$ \\
\hline MDA of mitochondria (nM/ mg protein) & $48.9 \pm 2.7$ & $49.1 \pm 3.9$ \\
\hline GSH of mitochondria (pM/ mg protein) & $8.8 \pm 2.2$ & $8.92 \pm 2.4$ \\
\hline SOD of mitochondria (U/ mg protein) & $70.2 \pm 5.8$ & $70.9 \pm 6.5$ \\
\hline Total sperm motility (\%) & & \\
\hline
\end{tabular}

Values are expressed as mean $\pm \operatorname{SD}(n=6)$.
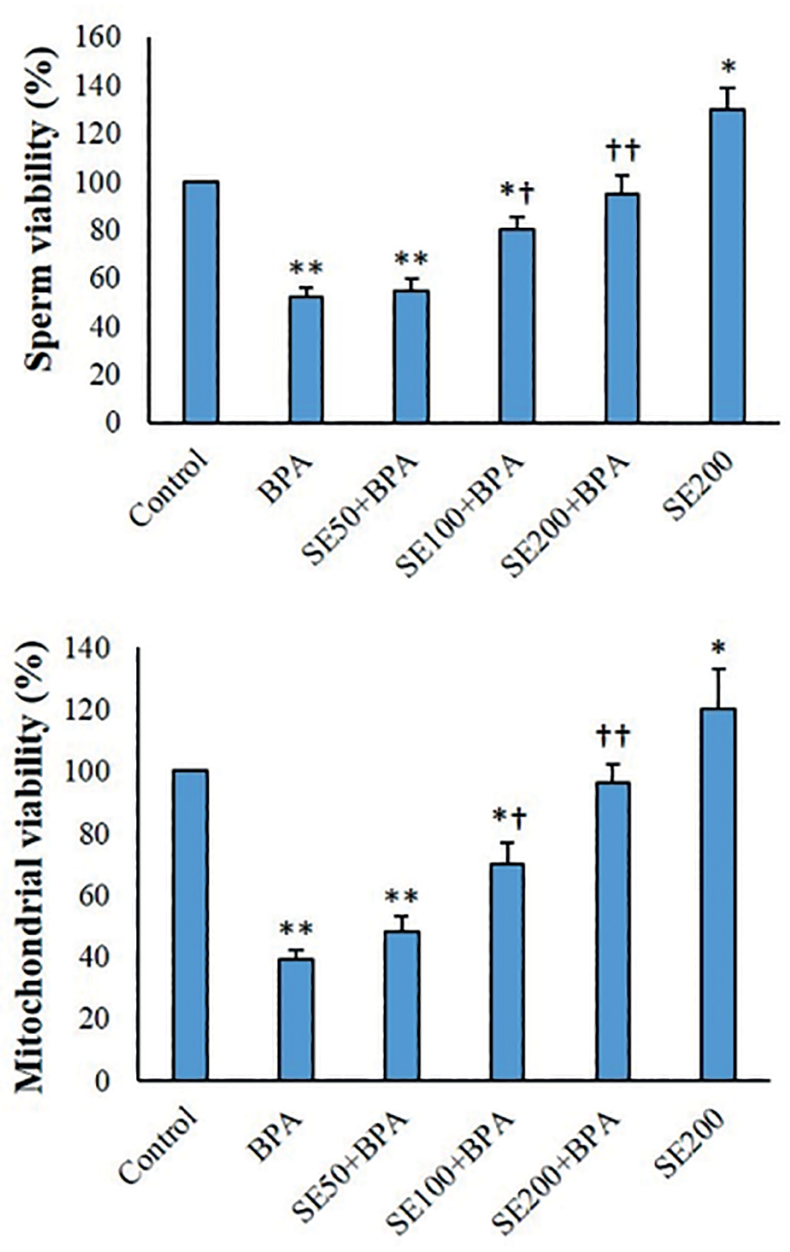

Figure 2. Viability of mitochondrial fractions and spermatozoa (mean $\pm \mathrm{SD} ; \mathrm{n}=6$ ).* $p<0.05, * * p<0.01$, ${ }^{+} p<0.05,{ }^{++} p<0.01$; *and ${ }^{+}$indicate comparisons against untreated control and BPA-treated groups, respectively.

mitochondria decreased in the group treated with SE compared with controls. SE concentration-dependently diminished ROS formation in the BPA-exposed mitochondrial fractions (Figure 3 ). GSH and SOD activity decreased after exposure to BPA $(p<0.01)$. In the SE-treated mitochondria, SOD and GSH activity was higher than the in the untreated (control) group. SE concentration-dependently

reversed the BPA-decreased antioxidant level of mitochondrial fractions (Figure 3 ).

\section{MMP Assay}

SE significantly increased the MMP of the isolated mitochondria $(p<0.05)$. In the BPA-exposed mitochondria, MMP decreased considerably compared with controls $(p<0.01)$. SE concentration-dependently elevated the MMP of BPA-exposed mitochondrial fractions (Figure 4).

\section{Sperm motility}

SE considerably increased total sperm motility in comparison with controls. Following exposure to BPA, the proportion of fast progressive spermatozoa $(p<0.05)$ and total sperm motility $(p<0.01)$ diminished considerably, while immotile sperm percentages significantly increased $(p<0.01)$. SE concentration-dependently diminished the proportions of immotile and fast progressive sperm, and increased total sperm motility (Table 3 and Figure 5).

\section{DISCUSSION}

The present study demonstrated that SE concentration-dependently reversed the motility and survival of BPA-treated spermatozoa. Consistent with our results, BPA diminished sperm quality in humans and some animal species (Kotwicka et al., 2016; Knez et al., 2014; Rahman et al., 2017).

Rezaeian et al. (2016) showed that SE increases the quality of sperm submitted to freezing and thawing procedures. Beneficial effects of SE on Monosodium glutamate-induced spermatogenesis damages have also been reported (Hamza \& Diab, 2020).

We observed that SE concentration-dependently enhanced viability, total motility, and fast progressive movement of BPA-exposed mouse sperm cells. In line with our findings, SE provided protection against reproductive system damages induced by zearalenone in male mice (Long et al., 2016). SE dramatically altered the changes induced by ethanol on sperm survival and motility to near-normal levels (Swathy et al., 2006). SE reportedly reversed the decreased number of spermatogonia and sperm cells induced by radiation (Bagheri et al., 2020). Beneficial impacts of SE on the quality of boar sperm have also been documented (Marin-Guzman et al., 1997; Bano et al., 2018).

As revealed in the results, SE effectively improved the motility of BPA-exposed spermatozoa. Improved motility of spermatozoa might be due to SE effects on mitochondrial mass or function (Shi et al., 2010).

This study did not intend to explain the effects SE produced on sperm survival. There is a possibility that SE improves sperm viability by suppressing cell death signaling. Ma et al. (2017) reported that SE prevents 

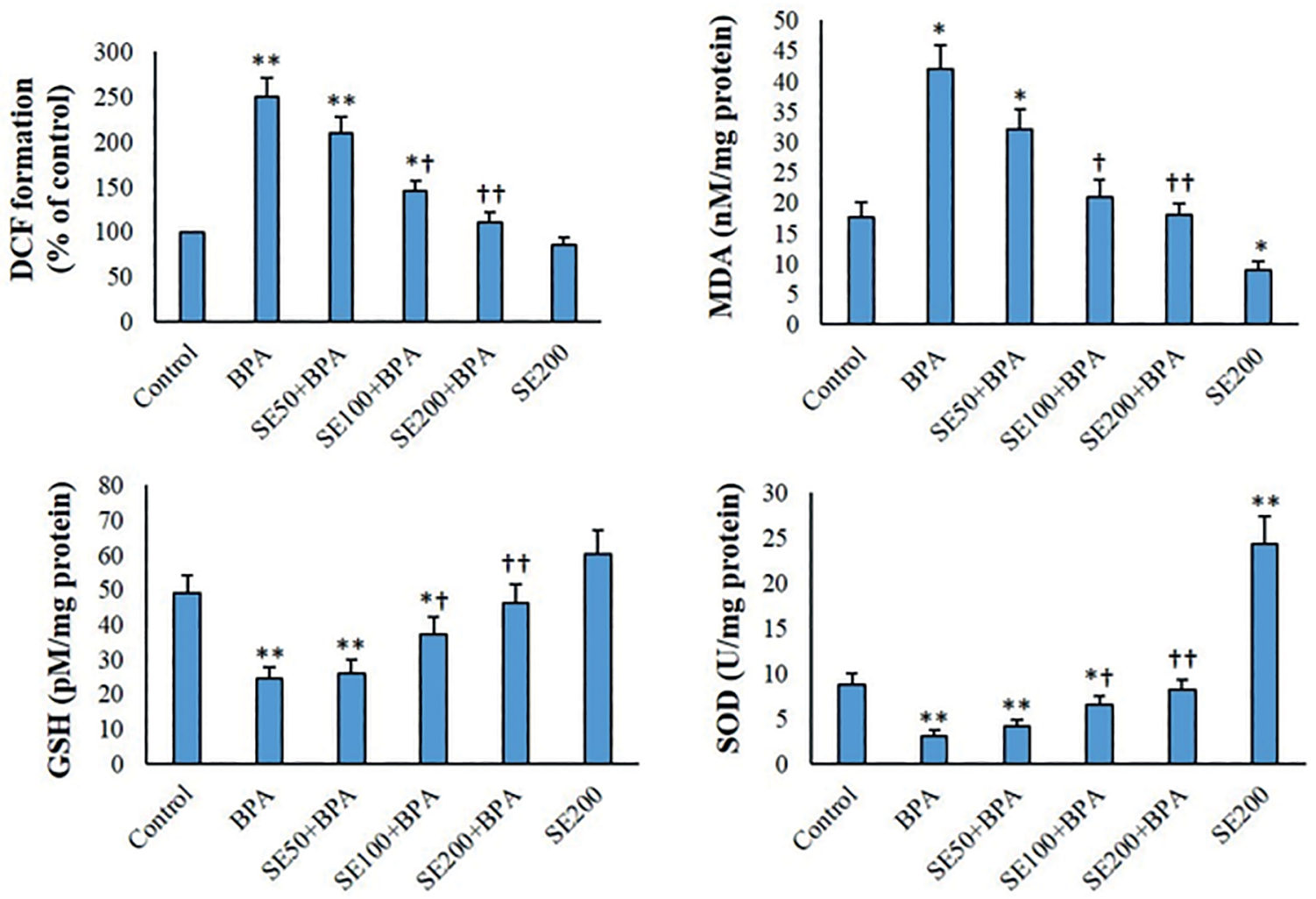

Figure 3. ROS, MDA, GSH, and SOD levels in the mitochondrial fractions (mean $\pm S D, n=6$ ). *and ${ }^{+}$indicate comparisons with untreated control and BPA-treated groups, respectively.

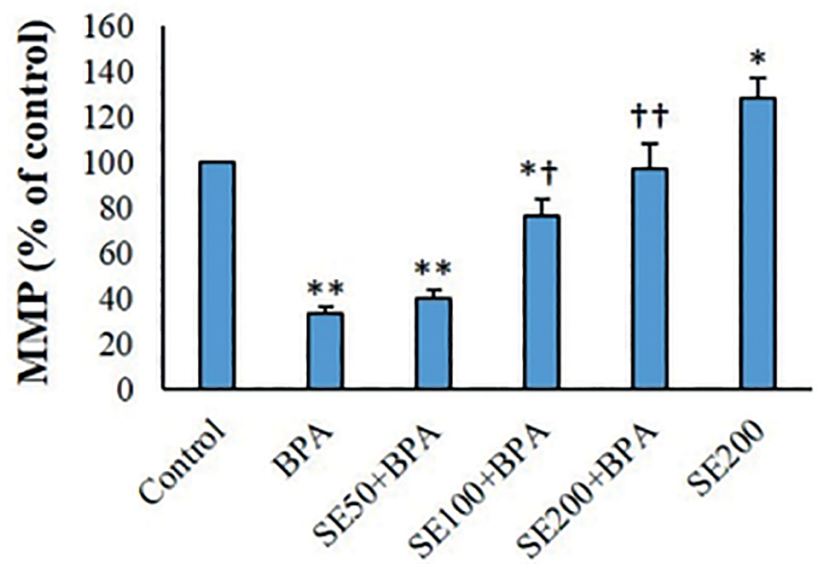

Figure 4. MMP measurement in different groups (mean $\pm \mathrm{SD}, \mathrm{n}=6)$. * and ${ }^{+}$indicate comparisons against untreated control and BPA-treated groups, respectively.

glutamate-induced cell death in HT22 hippocampal cells. Abu-El-Zahab et al. (2019) showed that SE inhibits apoptosis induced by cadmium in mouse hepatic tissue. SE prevented apoptosis induced by lead in chicken nervous tissues (Zhu et al., 2017). SE has an important role in the maintenance of follicles and suppression of apoptosis in ovaries (Yang et al., 2019). SE inhibits mitochondrial dysfunction and apoptosis in cadmium-induced ROS production within LLC-PK(1) cells (Zhou et al., 2009). Kahya et al. (2014) showed that mobile phone radiation $(900 \mathrm{MHz}$ ) induced apoptosis in breast cancer cells through increased oxidative stress. The authors reported that SE attenuated increased oxidative stress and apoptosis.
As mentioned in our results, BPA elevated MDA and ROS levels in testicular mitochondria. In line with our results, BPA increased ROS formation and MDA levels in sperm in previous studies (Rahman et al., 2019; Kaur et al., 2018). According to our results, SE reversed MMP, ROS production, MDA levels, and antioxidant biomarkers in the BPA-treated mitochondria. Therefore, SE may protect testicular mitochondria by decreasing oxidative stress. It has been shown that SE has a protective effect against mitochondrial oxidative disorders in different pathological cases. These results are in direct correlation with available evidence that indicates the beneficial impacts of SE on mitochondrial activity (Yeo \& Kang, 2007; Yoon et al., 2002). Neuroprotection provided by SE through reducing ROS production, preventing DNA oxidation, preserving MMP, and mitochondrial function have been reported by Mehta et al. (2012).

Ghafarizadeh et al. (2018) showed that MMP, sperm survival, total motility, and fast progressive sperm movement of infertile patients were considerably enhanced in SE-exposed samples after four hours of incubation. They concluded that SE protected spermatozoa from mitochondrial damage due to its antioxidant properties.

As shown in our results, BPA decreased the MMP of isolated mitochondria and SE concentration-dependently reversed the effects of BPA on MMP. Barbonetti et al. (2016) indicated that BPA diminished MMP and increased human spermatozoa loss. MMP correlates positively with progressive sperm motility and total sperm numbers (Zhang et al., 2016). The decrease in MMP caused by BPA was accompanied by increased oxidative stress in testicular isolated mitochondria, reduced sperm motility, and attenuated sperm viability. BPA can cause mitochondrial oxidative damage of testicles via increasing lipid peroxidation (del Hoyo et al., 2010), and lead to disruption of spermatozoa function (Catalá, 2009). 


\begin{tabular}{|l|c|c|c|c|}
\hline Table 3. Velocity distribution of sperm cells in various groups \\
\hline Groups & Fast progressive & Slow progressive & No progressive & Immotile \\
\hline Control & $39.9 \pm 4.2$ & $30.3 \pm 3.9$ & $16.8 \pm 2.5$ & $12.8 \pm 2.7$ \\
\hline BPA & $18.8 \pm 2.27^{* *}$ & $19.9 \pm 2.14^{*}$ & $28.5 \pm 3.25^{*}$ & $32.2 \pm 2.7^{* *}$ \\
\hline SE50 + BPA & $21.5 \pm 3.3^{* *}$ & $23.4 \pm 2.2$ & $28.1 \pm 2.7^{*}$ & $26.6 \pm 3.2^{* *}$ \\
\hline SE100 + BPA & $27.8 \pm 3.9^{*+}$ & $25.1 \pm 3.1$ & $24.9 \pm 3.4$ & $15.7^{*} \pm 2.9^{++}$ \\
\hline SE200 + BPA & $38.7 \pm 4.8^{+}$ & $22.9 \pm 3.8$ & $23.8 \pm 3.2$ & $13.9 \pm 1.7^{++}$ \\
\hline SE200 & $50.3 \pm 5.3^{++}$ & $30.2 \pm 3.6^{+}$ & $14.3 \pm 2.7$ & $6.2 \pm 1.2^{*++}$ \\
\hline
\end{tabular}

The mean \pm standard deviations are shown $(\mathrm{n}=6) .{ }^{*} p<0.05,{ }^{*} * p<0.01,{ }^{+} p<0.05,{ }^{++} p<0.01,{ }^{+++} p<0.001 ;{ }^{*}$ and ${ }^{+}$show comparisons against control and BPA-treated groups, respectively.

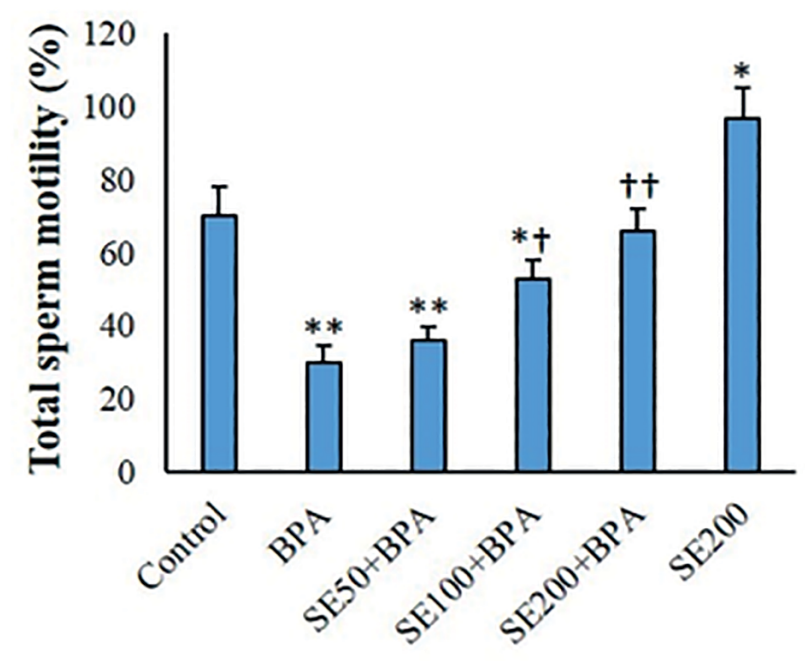

Figure 5. Total mouse sperm motility in the various groups (mean $\pm \mathrm{SD}, \mathrm{n}=6$ ). * and ${ }^{+}$indicate comparisons against control and BPA-treated groups, respectively.

SE reduces the glutamate-caused mitochondrial damage and ROS generation in HT22 neuronal cells (Kumari et al., 2012). SE has a crucial role in the enzymatic process for the elimination of ROS and helps to preserve membrane integrity. Treulen et al. (2016) showed that mitochondrial outer membrane permeabilization induction enhances intracellular ROS and reduces the mean velocity of human sperm cells.

\section{CONCLUSIONS}

Overall, SE concentration-dependently improved MMP and reduced mitochondrial oxidative stress. SE also effectively improved the survival and motility of mouse spermatozoa. It is suggested that SE might ameliorate BPA-caused mitochondrial damage and mouse sperm quality impairment by preventing oxidative stress.

\section{ACKNOWLEDGMENT}

Ahvaz Jundishapur University Student Research committee supported this study (Grant No: 97s-26).

\section{CONFLICT OF INTEREST}

The authors have no conflict of interest to declare.

\section{Corresponding author:}

Layasadat Khorsandi

Department of Anatomical Sciences

Faculty of Medicine

Ahvaz Jundishapur University of Medical

Sciences, Ahvaz, Iran

E-mail: khorsandi_cmrc@yahoo.com

\section{REFERENCES}

Abu-El-Zahab HSH, Hamza RZ, Montaser MM, El-Mahdi MM, Al-Harthi WA. Antioxidant, antiapoptotic, antigenotoxic, and hepatic ameliorative effects of L-carnitine and selenium on cadmium-induced hepatotoxicity and alterations in liver cell structure in male mice. Ecotoxicol Environ Saf. 2019;173:419-28. PMID: 30798185 DOI: 10.1016/j.ecoenv.2019.02.041

Anjum S, Rahman S, Kaur M, Ahmad F, Rashid H, Ansari RA, Raisuddin S. Melatonin ameliorates bisphenol A-induced biochemical toxicity in testicular mitochondria of mouse. Food Chem Toxicol. 2011;49:2849-54. PMID: 21840368 DOI: $10.1016 /$ j.fct.2011.07.062

Bagheri H, Salajegheh A, Javadi A, Amini P, Shekarchi B, Shabeeb D, Eleojo Musa A, Najafi M. Radioprotective Effects of Zinc and Selenium on Mice Spermatogenesis. J Biomed Phys Eng. 2020;10:707-12. PMID: 33364208 DOI: 10.31661/jbpe.v0i0.95

Bano I, Malhi M, Soomro S, Kandhro S, Awais M, Baloch S, Perveen, Sajjad H. Effect of Dietary Selenium Supplementation on Morphology and Antioxidant Status in Testes of Goat. J Basic Appl Sci. 2018;14:53-61. DOI: 10.6000/1927-5129.2018.14.08

Barbonetti A, Castellini C, Di Giammarco N, Santilli G, Francavilla S, Francavilla F. In vitro exposure of human spermatozoa to bisphenol A induces pro-oxidative/ apoptotic mitochondrial dysfunction. Reprod Toxicol. 2016;66:61-7. PMID: 27686954 DOI: 10.1016/j.reprotox.2016.09.014

Catalá A. Lipid peroxidation of membrane phospholipids generates hydroxy-alkenals and oxidized phospholipids active in physiological and/or pathological conditions. Chem Phys Lipids. 2009;157:1-11. PMID: 18977338 DOI: 10.1016/j.chemphyslip.2008.09.004 
Calvin HI, Cooper GW, Wallace E. Evidence that selenium in rat sperm is associated with a cysteine-rich structural protein of the mitochondrial capsules. Gamete Res. 1981;4:139-49. DOI: $10.1002 / \mathrm{mrd} .1120040208$

Chitra KC, Latchoumycandane C, Mathur PP. Induction of oxidative stress by bisphenol $A$ in the epididymal sperm of rats. Toxicology. 2003;185:119-27. PMID: 12505450 DOI: $10.1016 / \mathrm{S} 0300-483 \times(02) 00597-8$

Das RS, Ghosh SK. Long term effects of monosodium glutamate on spermatogenesis following neonatal exposure in albino mice--a histological study. Nepal Med Coll J. 2010;12:149-53. PMID: 21446362

del Hoyo P, García-Redondo A, de Bustos F, Molina JA, Sayed Y, Alonso-Navarro H, Caballero L, Arenas J, Agúndez JA, JiménezJiménez FJ. Oxidative stress in skin fibroblasts cultures from patients with Parkinson's disease. BMC Neurol. 2010;10:95. PMID: 20958999 DOI: 10.1186/1471-2377-10-95

Engel LS, Buckley JP, Yang G, Liao LM, Satagopan J, Calafat AM, Matthews CE, Cai Q, Ji BT, Cai H, Engel SM, Wolff MS, Rothman N, Zheng W, Xiang YB, Shu XO, Gao YT, Chow $\mathrm{WH}$. Predictors and variability of repeat measurements of urinary phenols and parabens in a cohort of Shanghai women and men. Environ Health Perspect. 2014;122:73340. PMID: 24659570 DOI: 10.1289/ehp. 1306830

Ghafarizadeh AA, Vaezi G, Shariatzadeh MA, Malekirad AA. Effect of in vitro selenium supplementation on sperm quality in asthenoteratozoospermic men. Andrologia. 2018;50: e12869. PMID: 28782302 DOI: $10.1111 /$ and.12869

Hamza RZ, Diab AEA. Testicular protective and antioxidant effects of selenium nanoparticles on Monosodium glutamate-induced testicular structure alterations in male mice. Toxicol Rep. 2020;7:254-60. PMID: 32025501 DOI: 10.1016/j.toxrep.2020.01.012

Ikezuki Y, Tsutsumi O, Takai Y, Kamei Y, Taketani Y. Determination of bisphenol A concentrations in human biological fluids reveals significant early prenatal exposure. Hum Reprod. 2002;17:2839-41. PMID: 12407035 DOI: 10.1093/ humrep/17.11.2839

Kahya MC, Nazıroğlu M, Çiğ B. Selenium reduces mobile phone (900 MHz)-induced oxidative stress, mitochondrial function, and apoptosis in breast cancer cells. Biol Trace Elem Res. 2014;160:285-93. PMID: 24965080 DOI: $10.1007 / \mathrm{s} 12011-014-0032-6$

Kamali Sangani A, Masoudi AA, Vaez Torshizi R. Association of mitochondrial function and sperm progressivity in slow- and fast-growing roosters. Poult Sci. 2017;96:2119. PMID: 27591282 DOI: 10.3382/ps/pew273

Kaur S, Bansal MP. Protective role of dietary-supplemented selenium and vitamin $\mathrm{E}$ in heat-induced apoptosis and oxidative stress in mice testes. Andrologia. 2015;47:1109-19. PMID: 25521483 DOI: https://doi.org/10.1111/and.12390

Kaur S, Saluja M, Bansal MP. Bisphenol A induced oxidative stress and apoptosis in mice testes: Modulation by selenium. Andrologia. 2018;50:e12834. PMID: 28719015 DOI: 10.1111 /and. 12834
Khurana A, Tekula S, Saifi MA, Venkatesh P, Godugu C. Therapeutic applications of selenium nanoparticles. Biomed Pharmacother. 2019;111:802-12. PMID: 30616079 DOI: 10.1016/j.biopha.2018.12.146

Knez J, Kranvogl R, Breznik BP, Vončina E, Vlaisavljević $V$. Are urinary bisphenol A levels in men related to semen quality and embryo development after medically assisted reproduction? Fertil Steril. 2014;101:215-21.e5. PMID: 24182411 DOI: 10.1016/j.fertnstert.2013.09.030

Konieczna A, Rutkowska A, Rachoń D. Health risk of exposure to Bisphenol A (BPA). Rocz Panstw Zakl Hig. 2015;66:5-11. PMID: 25813067

Kotwicka M, Skibinska I, Piworun N, Jendraszak M, Chmielewska $M$, Jedrzejczak P. Bisphenol A modifies human spermatozoa motility in vitro. J Med Sci. 2016;85:39-45. DOI: $10.20883 /$ jms.2016.5

Kumari S, Mehta SL, Li PA. Glutamate induces mitochondrial dynamic imbalance and autophagy activation: preventive effects of selenium. PLoS One. 2012;7:e39382. PMID: 22724008 DOI: 10.1371/journal.pone.0039382

Löfroth $M$, Ghasemimehr $M$, Falk $A$, Vult von Steyern $P$. Bisphenol A in dental materials - existence, leakage and biological effects. Heliyon. 2019;5:e01711. PMID: 31193754 DOI: $10.1016 /$ j.heliyon.2019.e01711

Long $M$, Yang $S$, Wang $Y$, Li $P$, Zhang $Y$, Dong $S$, Chen $X$, Guo J, He J, Gao Z, Wang J. The Protective Effect of Selenium on Chronic Zearalenone-Induced Reproductive System Damage in Male Mice. Molecules. 2016;21:1687. PMID: 27941626 DOI: $10.3390 /$ molecules21121687

Ma YM, Ibeanu G, Wang LY, Zhang JZ, Chang Y, Dong JD, Li PA, Jing L. Selenium suppresses glutamate-induced cell death and prevents mitochondrial morphological dynamic alterations in hippocampal HT22 neuronal cells. BMC Neurosci. 2017;18:15. PMID: 28103798 DOI: 10.1186/ s12868-017-0337-4

Marin-Guzman J, Mahan DC, Chung YK, Pate JL, Pope WF. Effects of dietary selenium and vitamin $E$ on boar performance and tissue responses, semen quality, and subsequent fertilization rates in mature gilts. J Anim Sci. 1997;75:29943003. PMID: 9374315 DOI: 10.2527/1997.75112994x

Mehta SL, Kumari S, Mendelev N, Li PA. Selenium preserves mitochondrial function, stimulates mitochondrial biogenesis, and reduces infarct volume after focal cerebral ischemia. BMC Neurosci. 2012;13:79. PMID: 22776356 DOI: $10.1186 / 1471-2202-13-79$

Mikołajewska K, Stragierowicz J, Gromadzińska J. Bisphenol A - Application, sources of exposure and potential risks in infants, children and pregnant women. Int J Occup Med Environ Health. 2015;28:209-41. PMID: 26182919 DOI: 10.13075/ijomeh.1896.00343

Rahman MS, Kwon WS, Karmakar PC, Yoon SJ, Ryu BY, Pang MG. Gestational Exposure to Bisphenol A Affects the Function and Proteome Profile of F1 Spermatozoa in Adult Mice. Environ Health Perspect. 2017;125:238-45. PMID: 27384531 DOI: $10.1289 /$ EHP378 
Rahman MS, Kang KH, Arifuzzaman S, Pang WK, Ryu DY, Song WH, Park YJ, Pang MG. Effect of antioxidants on BPA-induced stress on sperm function in a mouse model. Sci Rep. 2019;9:10584. PMID: 31332285 DOI: 10.1038/ s41598-019-47158-9

Rezaeian Z, Yazdekhasti H, Nasri S, Rajabi Z, Fallahi P, Amidi F. Effect of selenium on human sperm parameters after freezing and thawing procedures. Asian Pac J Reprod. 2016;5:462-6. DOI: 10.1016/j.apjr.2016.11.001

Saaranen M, Suistomaa U, Vanha-Perttula T. Semen selenium content and sperm mitochondrial volume in human and some animal species. Hum Reprod. 1989;4:304-8. PMID: 2715306 DOI: 10.1093/oxfordjournals.humrep.a136893

Shi L, Yue W, Zhang C, Ren Y, Zhu X, Wang Q, Shi L, Lei F. Effects of maternal and dietary selenium (Se-enriched yeast) on oxidative status in testis and apoptosis of germ cells during spermatogenesis of their offspring in goats. Anim Reprod Sci. 2010;119:212-8. PMID: 20226605 DOI: 10.1016/j.anireprosci.2010.02.012

Swathy SS, Panicker S, Indira M. Effect of exogenous selenium on the testicular toxicity induced by ethanol in rats. Indian J Physiol Pharmacol. 2006;50:215-24. PMID: 17193892

Treulen F, Uribe P, Boguen R, Villegas JV. Mitochondrial outer membrane permeabilization increases reactive oxygen species production and decreases mean sperm velocity but is not associated with DNA fragmentation in human sperm. Mol Hum Reprod. 2016;22:83-92. PMID: 26621869 DOI: $10.1093 / \mathrm{molehr} /$ gav067

Tyl RW, Myers CB, Marr MC, Sloan CS, Castillo NP, Veselica MM, Seely JC, Dimond SS, Van Miller JP, Shiotsuka RN, Beyer D, Hentges SG, Waechter JM Jr. Two-generation reproductive toxicity study of dietary bisphenol $A$ in CD-1 (Swiss) mice. Toxicol Sci. 2008;104:362-84. PMID: 18445619 DOI: $10.1093 /$ toxsci/kfn084
Ullah A, Pirzada M, Jahan S, Ullah H, Shaheen G, Rehman $H$, Siddiqui MF, Butt MA. Bisphenol $A$ and its analogs bisphenol B, bisphenol $F$, and bisphenol S: Comparative in vitro and in vivo studies on the sperms and testicular tissues of rats. Chemosphere. 2018;209:508-16. PMID: 29940534 DOI: 10.1016/j.chemosphere.2018.06.089

Ursini F, Maiorino M, Gregolin C. The selenoenzyme phospholipid hydroperoxide glutathione peroxidase. Biochim Biophys Acta. 1985;839:62-70. PMID: 3978121 DOI: 10.1016/0304-4165(85)90182-5

Yang H, Qazi IH, Pan B, Angel C, Guo S, Yang J, Zhang Y, Ming Z, Zeng C, Meng Q, Han H, Zhou G. Dietary Selenium Supplementation Ameliorates Female Reproductive Efficiency in Aging Mice. Antioxidants (Basel). 2019;8:634. PMID: 31835711 DOI: $10.3390 / a n t i o x 8120634$

Yeo JE, Kang SK. Selenium effectively inhibits ROS-mediated apoptotic neural precursor cell death in vitro and in vivo in traumatic brain injury. Biochim Biophys Acta. 2007;1772:1199210. PMID: 17997286 DOI: 10.1016/j.bbadis.2007.09.004

Yoon SO, Kim MM, Park SJ, Kim D, Chung J, Chung AS. Selenite suppresses hydrogen peroxide-induced cell apoptosis through inhibition of ASK1/JNK and activation of PI3-K/ Akt pathways. FASEB J. 2002;16:111-3. PMID: 11709494 DOI: $10.1096 /$ fj.01-0398fje

Zhang G, Wang $Z$, Ling $X$, Zou $P$, Yang $H$, Chen $Q$, Zhou N, Sun L, Gao J, Zhou Z, Cao J, Ao L. Mitochondrial Biomarkers Reflect Semen Quality: Results from the MARCHS Study in Chongqing, China. PLoS One. 2016;11:e0168823. PMID: 28006017 DOI: 10.1371/journal.pone.0168823

Zhou Y], Zhang SP, Liu CW, Cai YQ. The protection of selenium on ROS mediated-apoptosis by mitochondria dysfunction in cadmium-induced LLC-PK(1) cells. Toxicol In Vitro. 2009;23:28894. PMID: 19135140 DOI: $10.1016 / j . t i v .2008 .12 .009$

Zhu Y, Jiao X, An Y, Li S, Teng X. Selenium against lead-induced apoptosis in chicken nervous tissues via mitochondrial pathway. Oncotarget. 2017;8:108130-45. PMID: 29296229 DOI: 10.18632/oncotarget.22553 